\title{
Design and Evaluation of a Multi-layer Interior PM Synchronous Motor for High-Speed Drive Applications
}

\author{
Sung-Il Kim ${ }^{1}$ and Jung-Pyo Hong ${ }^{2 *}$ \\ ${ }^{1}$ Motor R\&D Group, Digital Appliances, Samsung Electronics, Suwon 16677, Korea \\ ${ }^{2}$ Department of Automotive Engineering, Hanyang University, Seoul 04763, Korea
}

(Received 7 June 2016, Received in final form 4 July 2016, Accepted 14 July 2016)

\begin{abstract}
In general, surface mounted PM synchronous motors (SPMSMs) are mainly adopted as a driving motor for high-speed applications, because they have high efficiency and high power density. However, the SPMSMs have some weak points such as the increase of magnetic reluctance and additional losses as a consequence of using a non-magnetic sleeve. Especially, the magneto-motive force (MMF) in the air-gap of the SPMSMs is weakened due to the magnetically increased resistance. For that reason, a large amount of PM is consumed to meet the required MMF. Nevertheless, it cannot help using the sleeve in order to maintain the mechanical integrity of a rotor assembly in high-speed rotation. Thus, in this paper, a multi-layer interior PM synchronous motor (IPMSM) not using the sleeve is presented and designed as an alternative of a SPMSM. Both motors are evaluated by test results based on a variety of characteristics required for an air blower system of a fuel cell electric vehicle.
\end{abstract}

Keywords : air blower, driving motor, fuel cell electric vehicle, high-speed, permanent magnet synchronous motor

\section{Introduction}

In recent years, high-speed electrical machines have been mainly adopted for a compact driving system in various industrial applications. In high-speed drive systems, gearless directly coupled high-speed machines decrease the number of drive components, enhance the system reliability and prevent the cost, maintenance, and losses related to gears. Moreover, noise can also be reduced dramatically by eliminating an additional transmission system. Accordingly, such machines are especially fitted for automotive applications where space, energy savings, and system reliability are critical [1-3].

Thanks to high efficiency and high power density, permanent magnet synchronous motors (PMSMs) among various motors such as an induction motor and a switched reluctance motor are becoming more and more favored to a high-speed machine [4, 5]. Especially, on account of relatively simple rotor structure, a surface-mounted PMSM (SPMSM) is principally employed for the high-speed machines. Nevertheless, the SPMSM has some weak points

(C)The Korean Magnetics Society. All rights reserved.

*Corresponding author: Tel: +82-2-2220-0455

Fax: +82-2-2220-4465, e-mail: hongjp@hanyang.ac.kr due to a non-magnetic sleeve exiting to maintain the mechanical integrity of the rotor assembly in high-speed rotation [6]. First, magnetic reluctance additionally increases by the thickness of the sleeve including air-gap. As a result, a large amount of permanent magnet (PM) is consumed in order to secure the magneto-motive force (MMF) required in the air-gap [7]. Next, manufacturing process such as shrink fit is added to assemble the sleeve on the PM. Finally, eddy current loss in the sleeve with electrical conductivity is generated by the slot or MMF harmonics [8-10]. Therefore, in this paper, a multi-layer interior permanent magnet synchronous motor (IPMSM) not using the sleeve is presented for high-speed applications.

The IPMSM does not essentially need the sleeve because PM is inserted inside the rotor core. In addition, if the amount of PM and rotor volume is identical, the IPMSM using a proper current vector control generally can obtain higher torque than the SPMSM because it can use not only magnetic torque but reluctance torque [11,12]. However, the IPMSM also has some problems for highspeed operation. In order to meet both electromagnetic performance and mechanical strength, special rotor design is typically required compared with the SPMSM. In particular, at high rotational speed, it is highly difficult to 
design so-called bridges or ribs to withstand high stress concentration without losing the performance [13-16]. Thus, in this paper, a 2-pole IPMSM with a multi-layer rotor structure is designed and tested for verifying its performance and feasibility as a high-speed drive. Especially, the IPMSM are experimentally analyzed by a comparison with the SPMSM applied for driving an air blower of a fuel cell electric vehicle (FCEV).

\section{IPMSM Design for Air Blower}

First, except the rotor configuration, all design conditions for the IPMSM such as stator and rotor dimensions, the number of turns per phase, and voltage and current limit are identical to those of the SPMSM. Second, the specifications and dimensions of the SPMSM are displayed in Table 1. Finally, the IPMSM design is focused to ensure equal performances compared to the SPMSM and reduce total amount of PM.

\subsection{Parametric Design}

The rotor design of IPMSM is much more complicated than that of SPMSM because the parameters such as back-EMF and inductance change irregularly according to the arrangement of PM and flux barrier inside the rotor [17-19]. Therefore, in this paper, a parametric design [2022] is carried out before the rotor shape design. The design is to determine the target range of motor parameters in order to meet both design limitations and required performances. The range obtained by regulating the value of flux linkage and d-axis inductance in (1), (2), and (4) expressed as a voltage and torque equation of the IPMSM [23] becomes a main criterion for designing the initial rotor configuration. At this time, the core loss

Table 1. Dimensions and specifications of SPMSM.

\begin{tabular}{ccc}
\hline \hline Items & Value (unit) & Condition \\
\hline Stator outer diameter & $88.0 \mathrm{~mm}$ & Including sleeve \\
Rotor outer diameter & $35.2 \mathrm{~mm}$ & thickness $1.5 \mathrm{~mm}$ \\
\hline Electrical steel & $35 \mathrm{PN} 440$ & \\
Air-gap & $2.0 \mathrm{~mm}$ & \\
Stack length & $35.0 \mathrm{~mm}$ & \\
Number of poles/slots & $2 / 18$ & Short pitch winding \\
Remanent flux density of PM & $1.18 \mathrm{~T}$ & NdFeB magnet \\
Number of series turns per phase & 33 & \\
\hline Line-to-line input voltage limit & $152.7 \mathrm{~V}$ rms & \\
Input current limit & $40.0 \mathrm{~A}_{\mathrm{rms}}$ & Under $85^{\circ} \mathrm{C}$ after \\
Peak output power & $8.0 \mathrm{~kW}$ & 20 min. operation \\
Maximum top speed & $40,000 \mathrm{rpm}$ & at full load \\
Cooling method & Air forced & \\
\hline
\end{tabular}

Table 2. Measured parameters of SPMSM.

\begin{tabular}{cc}
\hline \hline Parameters & Value (unit) \\
\hline Phase back-EMF & $76 \mathrm{~V}_{\text {rms }} @ 40,000 \mathrm{rpm}$ \\
d-axis inductance & $0.184 \mathrm{mH}$ \\
Winding resistance & $58.9 \mathrm{~m}$ \\
\hline
\end{tabular}

Table 3. Target range for IPMSM design.

\begin{tabular}{cc}
\hline \hline Parameters & Value (unit) \\
\hline Phase back-EMF & $56 \sim 60 \mathrm{~V}_{\text {rms }} @ 40,000 \mathrm{rpm}$ \\
d-axis inductance & $0.22 \sim 0.26 \mathrm{mH}$ \\
Saliency ratio & More than 2.2 \\
\hline
\end{tabular}

resistance [24-27] of the IPMSM is replaced with that of the SPMSM, and the design constraints are given in (5). Finally, the measured parameters of the SPMSM shown in Table 2 are based in order to search the target range. The reason is that the same stator and coil winding is applied to both motors.

$$
\begin{aligned}
& {\left[\begin{array}{l}
v_{d} \\
v_{q}
\end{array}\right]=R_{a}\left[\begin{array}{c}
i_{o d} \\
i_{o q}
\end{array}\right]+\left(1+\frac{R_{a}}{R_{c}}\right)\left[\begin{array}{l}
v_{o d} \\
v_{o q}
\end{array}\right]} \\
& {\left[\begin{array}{l}
v_{o d} \\
v_{o q}
\end{array}\right]=\left[\begin{array}{cc}
0 & -\omega L_{q} \\
\omega L_{d} & 0
\end{array}\right]\left[\begin{array}{l}
v_{o d} \\
v_{o q}
\end{array}\right]+\left[\begin{array}{c}
0 \\
\omega \psi_{a}
\end{array}\right]} \\
& i_{o d}=i_{d}-i_{c d}, i_{o q}=i_{q}-i_{c q} \\
& T=P_{n}\left[\psi_{a} i_{o q}+\left(L_{d}-L_{q}\right) i_{o d} i_{o q}\right] \\
& I_{a}=\sqrt{i_{d}^{2}+i_{q}^{2}} \leq I_{a m}, V_{a}=\sqrt{v_{d}^{2}+v_{q}^{2}} \leq V_{a m}
\end{aligned}
$$

where $i_{d}, i_{q}$ are $\mathrm{d}$ - and q-axis components of armature current; $i_{c d}, i_{c q}$ are d- and q-axis components of core loss current; $v_{d}, v_{q}$ are d-and q-axis components of voltage; $\psi_{a}$ is $\sqrt{3 / 2} \psi_{f} ; \psi_{f}$ is peak flux linkage of PM; $R_{a}$ is armature winding resistance; $R_{c}$ is core loss resistance; $L_{d}, L_{q}$ are inductance along d- and q-axis; $P_{n}$ is number of pole pairs; $I_{a m}, V_{a m}$ are peak values of current and voltage.

Figure 1 and Fig. 2 show the results predicted by the parametric design at $40,000 \mathrm{rpm}$. The figures indicate that the region of parameters meeting the specifications given in Table 1 varies according to the saliency ratio, the ratio between $\mathrm{d}$ - and q-axis inductance. That is, if the saliency is high, the level of required back-EMF is lower thanks to the increase of reluctance torque. If design conditions listed in Table 1 are unchanged, that means it is possible to satisfy the required torque with relatively small amount of PM. In the end, the target range presented in Table 3 is decided by the following conditions: 


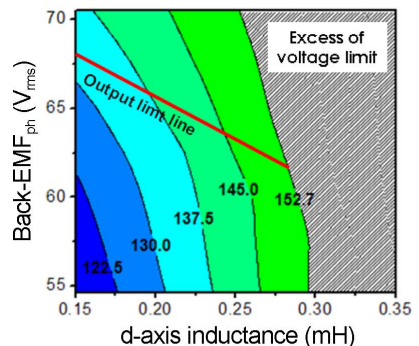

(a)

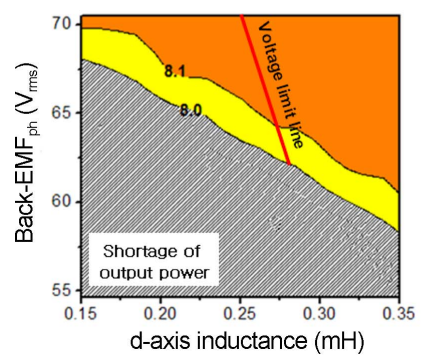

(c)

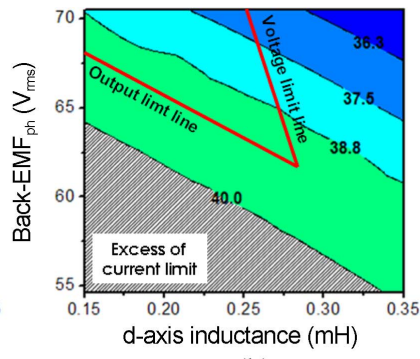

(b)

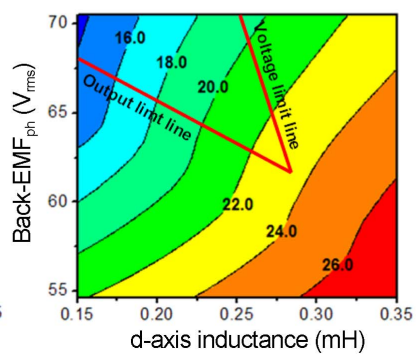

(d)
Fig. 1. (Color online) Parametric design map at saliency ratio 1.75 and 40,000 rpm: (a) Line-to-line voltage [V], (b) Current [A], (c) Output power [kW], (d) Current phase angle [deg.]

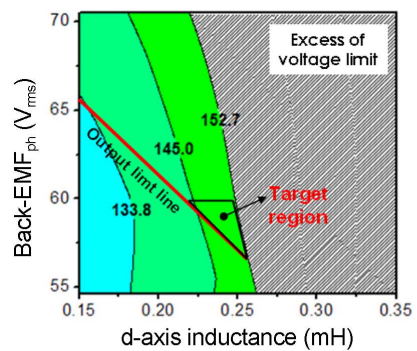

(a)

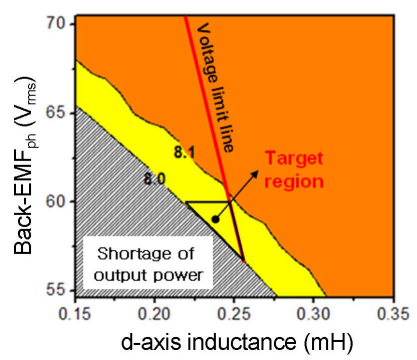

(c)

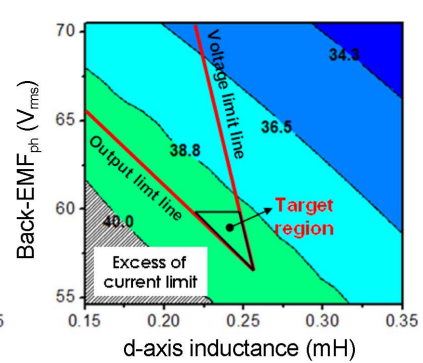

(b)

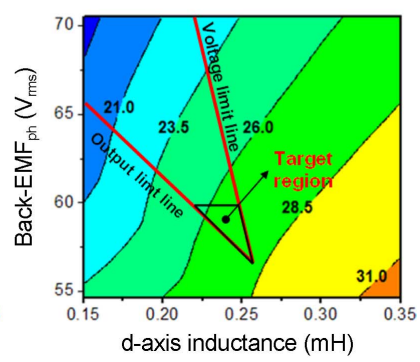

(d)
Fig. 2. (Color online) Parametric design map at saliency ratio 2.2 and 40,000 rpm: (a) Line-to-line voltage [V], (b) Current [A], (c) Output power [kW], (d) Current phase angle [deg.]

- Input current and voltage are limited as given in Table 1.

- Within attainable saliency ratio, the range of backEMF is selected as low as possible.

- Inductance of the IPMSM compared to the SPMSM will be increased because the reluctance of magnetic circuit is decreased through eliminating the sleeve and reducing the thickness of PM.

\subsection{Rotor Design and Fabrication}

The rotor design of the IPMSM operated at high speed is a challenging task thanks to the conflict between electromagnetic performance and mechanical strength. For example, the rotor with thin ribs or bridges results in better performance due to less leakage flux, but it may not be strong enough to withstand the centrifugal forces with the rotor speed increase. Moreover, the output performance of the IPMSM is also greatly affected by the configuration and position of magnets and flux barriers in the rotor core and the number of magnet layers [19, 28]. Therefore, in this paper, an experimental design based on finite element analysis (FEA) is executed for the more effective rotor design [29, 30]. In particular, in [30], the analysis results for optimizing the rotor shape were presented in detail. Figure 3 shows the safety factor of final rotor configuration is 1.4 at $40,000 \mathrm{rpm}$ (electrical steel yield stress: $305 \mathrm{MPa}$ ). Even though the safety

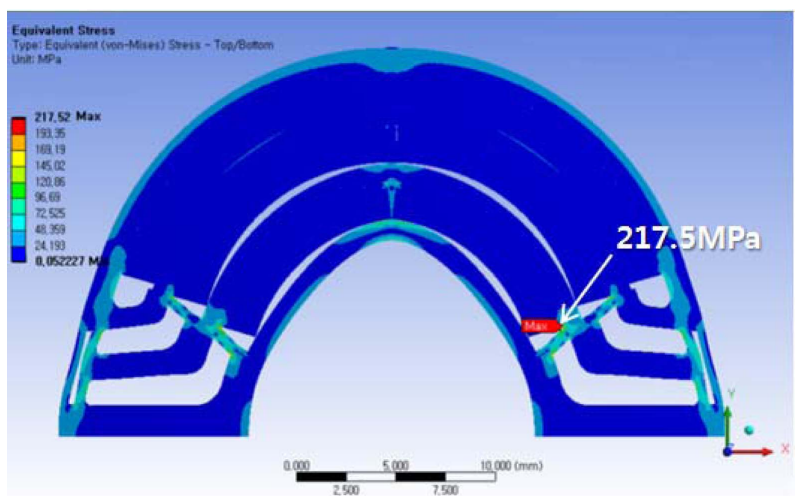

Fig. 3. (Color online) Stress analysis of final rotor shape under centrifugal force at 40,000 rpm.

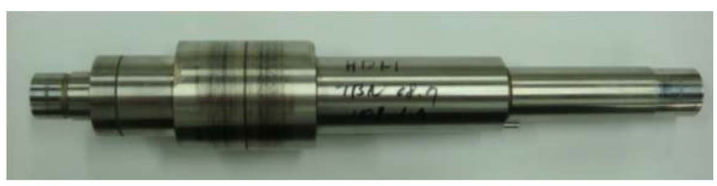

(a)

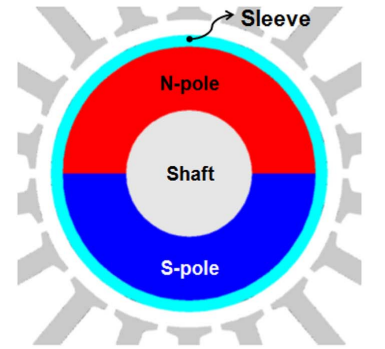

(b)

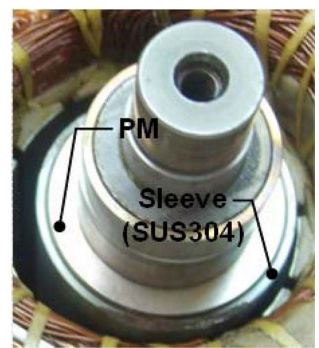

(c)
Fig. 4. (Color online) Rotor configurations of SPMSM: (a) Rotor assembly, (b) FEA model, (c) Fabricated model. 


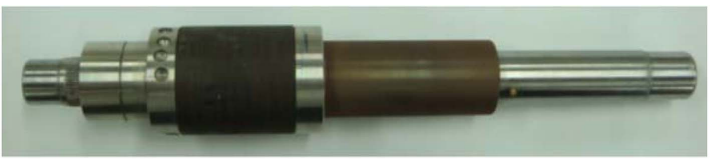

(a)

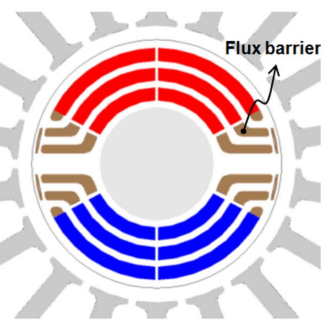

(b)

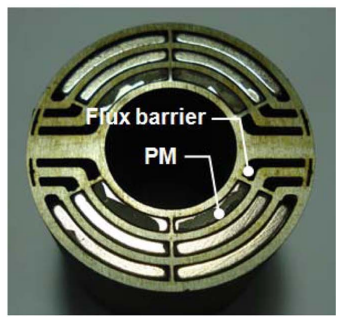

(c)
Fig. 5. (Color online) Rotor configurations of IPMSM: (a) Rotor assembly, (b) FEA model, (c) Fabricated model.

factor is somewhat low, the computed maximum stress does not exceed the fatigue limit based on the steel data supplied by a manufacturer.

The fabricated rotors of SPMSM and IPMSM are compared in Fig. 4 and Fig. 5. The salient feature in the rotor of IPMSM is that the rotor has multi-layer magnets in order to achieve high saliency. The amount of PM used for the IPMSM is reduced approximately by $53 \%$ compared with the SPMSM. Moreover, as shown in Fig. 6 and Fig. 7, the parameters estimated by FEA meet the target range given in Table 3. Especially, each phase back-EMF of the SPMSM and IPMSM is predicted as 76 Vrms and 56.8 Vrms at 40,000 rpm because the backEMFs measured at $1,000 \mathrm{rpm}$ are $1.9 \mathrm{Vrms}$ and 1.42 Vrms. In the end, the IPMSM with unmagnetized magnets is fabricated in order to measure its mechanical loss. Fig. 8 shows the mechanical loss measured up to 25,000 rpm due to the speed limitation of test apparatus. Although there is a difference between the both motors in terms of the mechanical loss, it is assumed that those of both motors are equal in this paper because their rotor size, air-

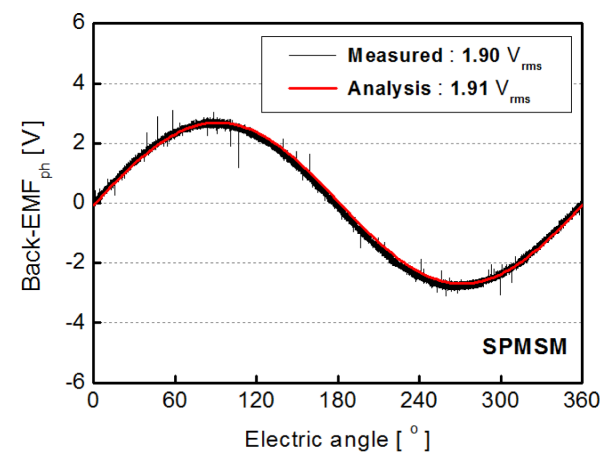

(a) gap length, and bearing type influencing the loss are the same $[4,5]$.

\section{Air Blower System Test}

In this section, the performances of SPMSM and IPMSM are compared in the circumstance similar to the air blower system of a FCEV. Especially, efficiency, pressure ratio, and transient response of the system are measured for the comparison.

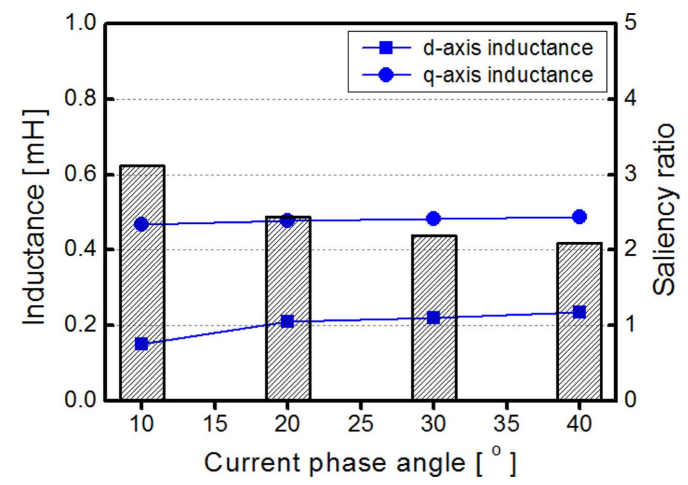

Fig. 7. (Color online) d- and q-axis inductance of IPMSM calculated at $40 \mathrm{~A}_{\mathrm{rms}}$.

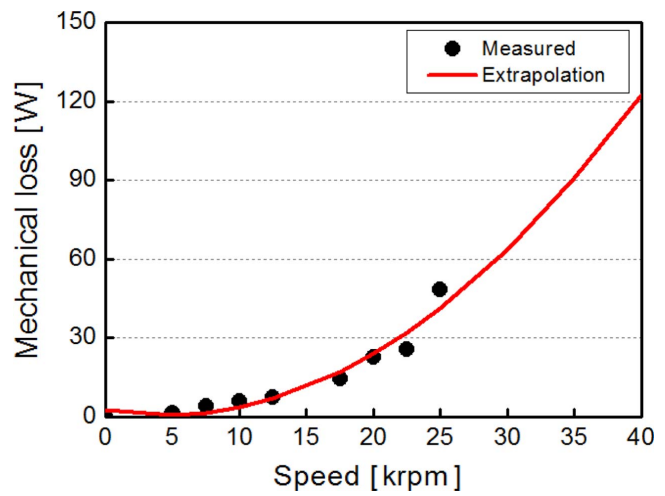

Fig. 8. (Color online) Measured mechanical loss of IPMSM with unmagnetized magnets.

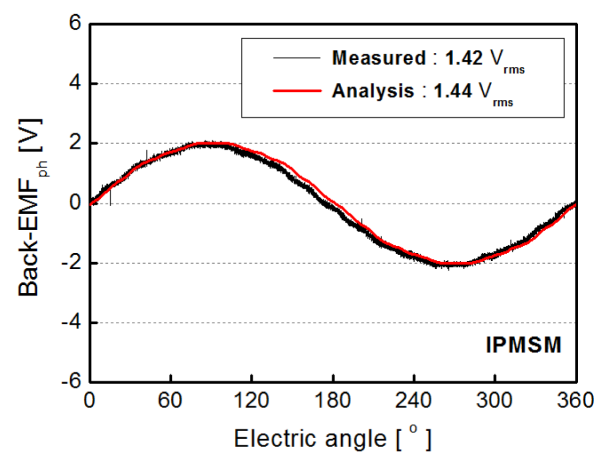

(b)

Fig. 6. (Color online) Phase back-EMF waveforms predicted and measured at 1,000 rpm: (a) SPMSM, (b) IPMSM. 


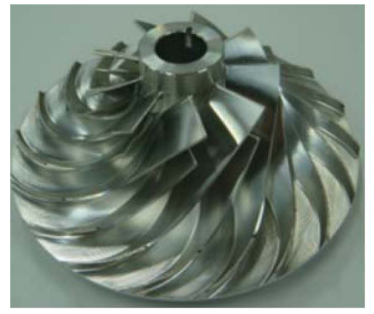

(a)

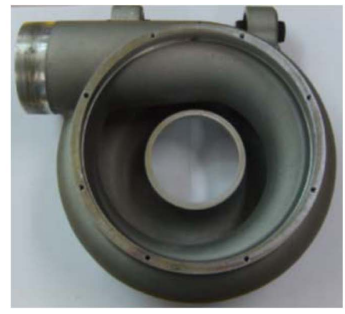

(b)

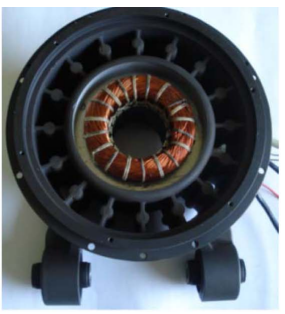

(c)

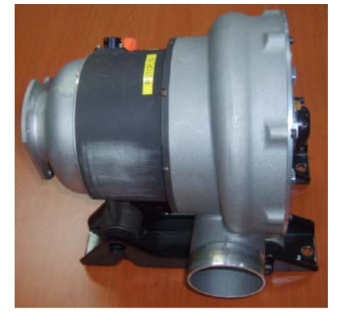

(d)

Fig. 9. (Color online) Components of an air blower: (a) Impeller, (b) Volute, (c) Stator winding, (d) Assembly configuration.

\subsection{Efficiency and Pressure Ratio}

Figure 9 shows an air blower and its components identically applied to the SPMSM and IPMSM. It is not easy to carry out the load test of the motors at high speed. Therefore, in this paper, both motors are indirectly evaluated through the test of an air blower system as shown in Fig. 10. Above all, the system and blower efficiency is calculated by (6) and (7) respectively. It is difficult to measure only efficiency of the motors due to the impeller efficiency. However, the performance difference of air blower system is mostly caused by the motors because all the test conditions are the same except the driving motor.

$$
\begin{aligned}
& \text { System Eff. }=\frac{\text { Aerodynamic Power }}{\text { Controller Input Power }} \\
& \text { Blower Eff. }=\frac{\text { Aerodynamic Power }}{\text { Controller Ouput Power }}
\end{aligned}
$$

Aerodynamic Power $=C_{p_{\_} \text {air }} \times Q_{\text {inlet_air }} \times\left(T_{\text {inlet }}+273.15\right)$

$$
\times\left[P R^{2} \times\left\{\left(k_{\text {air }}-1\right) / k_{\text {air }}\right\}-1\right]
$$

where $C_{p_{-} \text {air }}$ is specific heat of air at $300 \mathrm{~K} ; Q_{\text {inlet_air }}$ is inlet flow; $T_{\text {inlet }}$ is inlet ambient temperature; $P R$ is pressure ratio between inlet and outlet; $k_{\text {air }}$ is specific heat ratio of air.

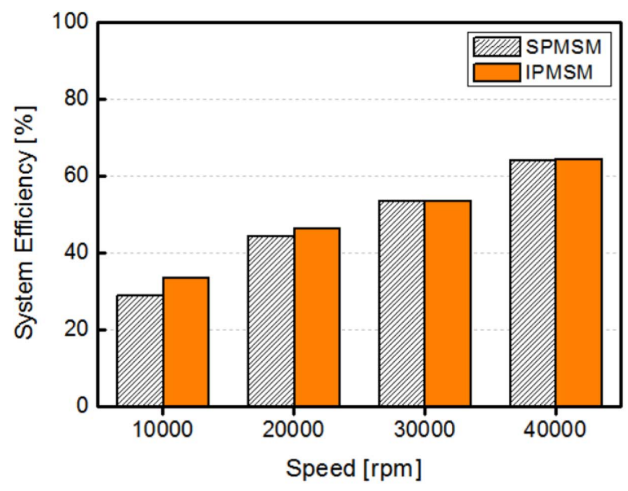

(a)

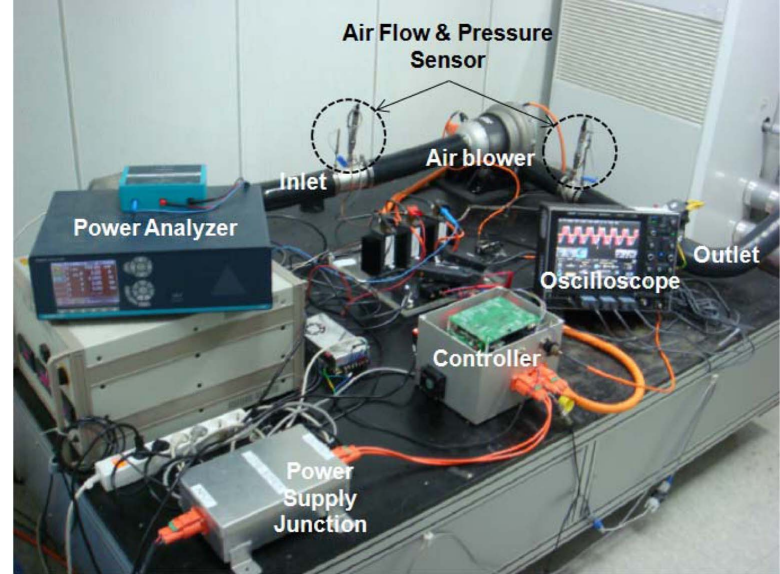

Fig. 10. (Color online) Testing apparatus of an air blower system.

The efficiency measured at the system and blower is given in Fig. 11. The result shows the system efficiency almost depends on the blower efficiency. In particular, the efficiency of motor driving the blower has a decisive effect on the result because the pressure ratio of the air blower driven by each motor is the same as displayed in Fig. 12(a). That is, in (8), there is no difference between their aerodynamic powers and it can be assumed that the shaft powers of both motors are almost identical. Thus, as

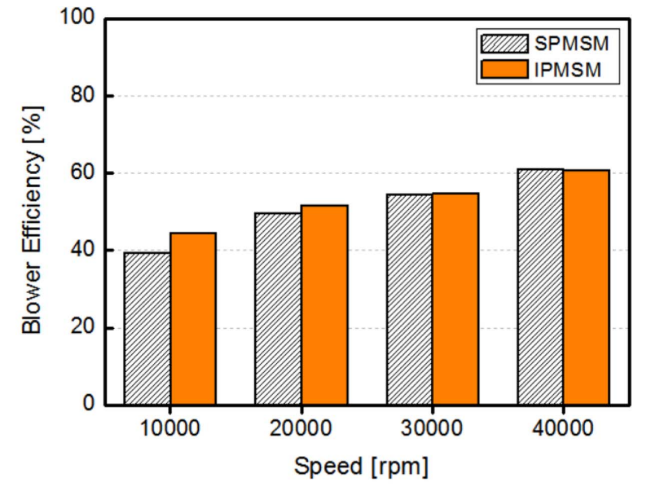

(b)

Fig. 11. (Color online) Efficiency measured according to speed: (a) Air blower system, (b) Air blower. 


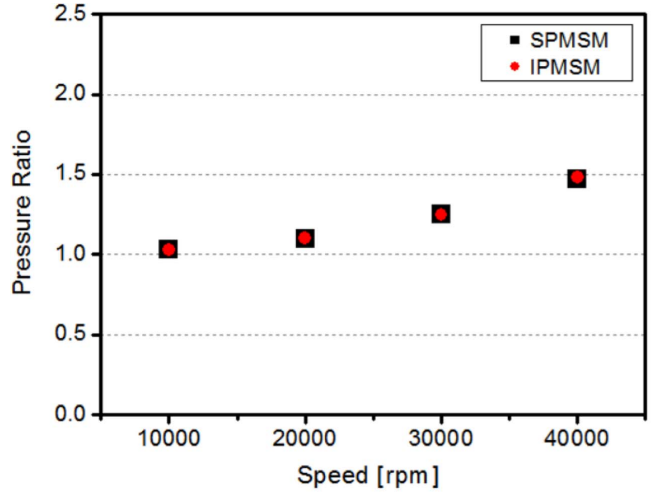

(a)

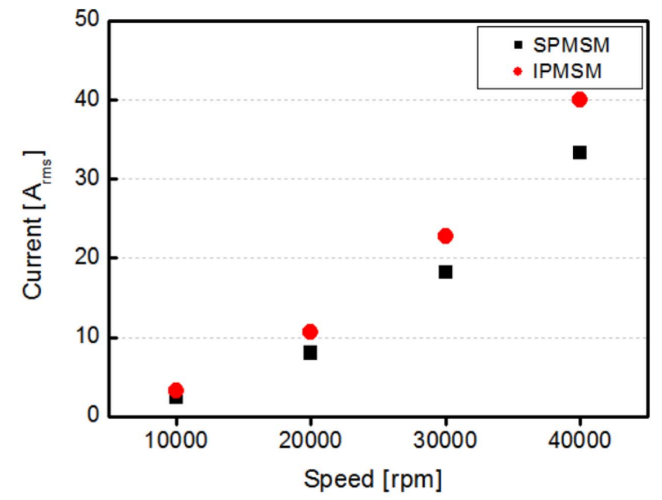

(b)

Fig. 12. (Color online) Measured pressure ratio and current: (a) Pressure ratio, (b) Input current.

shown in Fig. 11, the obvious difference in the efficiency under 30,000 rpm is influenced by the losses generated in the motors. Figure 13 shows their no-load core losses predicted by FEA [31]. The core losses are basically affected by the time rate of the change of magnetic flux density at the motor cores. As a result, the core loss of the SPMSM using a large amount of PM to obtain high backEMF cannot help but be great compared to that of the IPMSM at no-load condition. In order to explain the efficiency difference more clearly, Fig. 14 displays the total losses and output powers based on FEA. In the results, the mechanical loss given in Fig. 8 is applied to

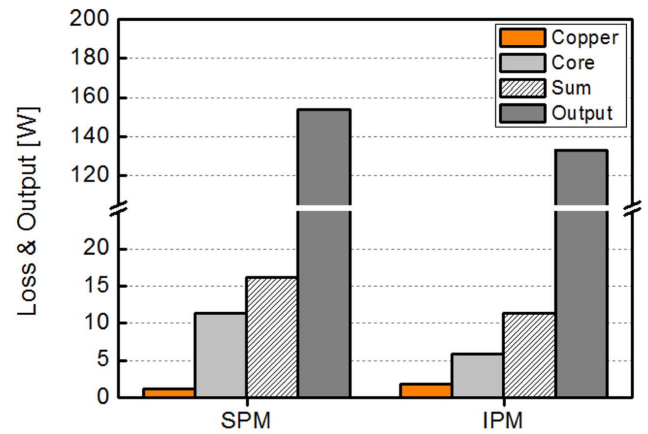

(a)

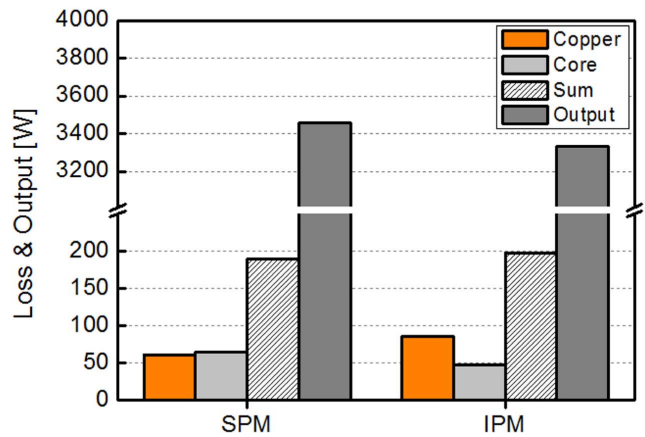

(c)

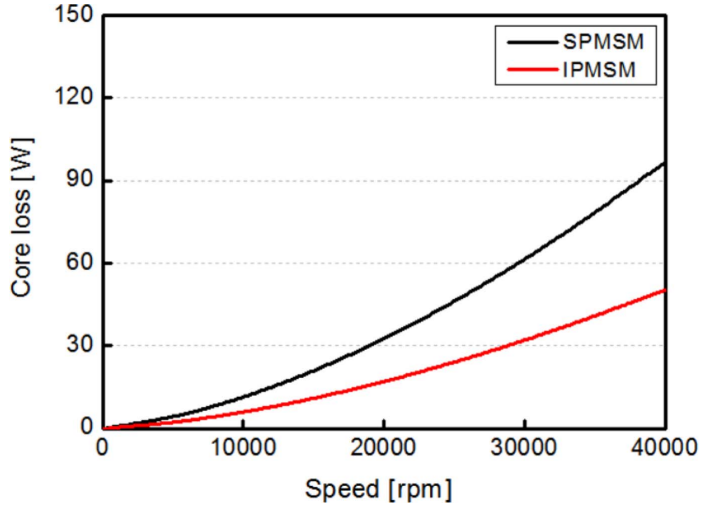

Fig. 13. (Color online) No-load core loss estimated by FEA.

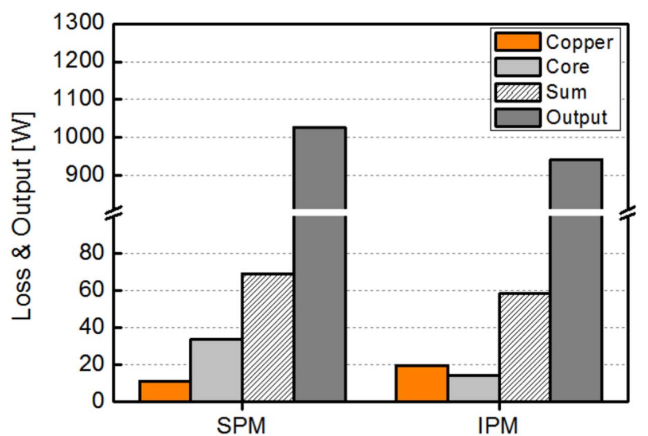

(b)

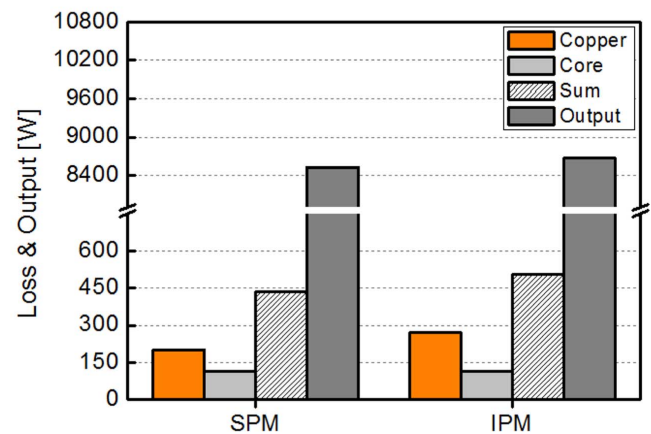

(d)

Fig. 14. (Color online) Loss distributions and outputs at each speed: (a) 10,000 rpm, (b) 20,000 rpm, (c) 30,000 rpm, (d) 40,000 rpm. 


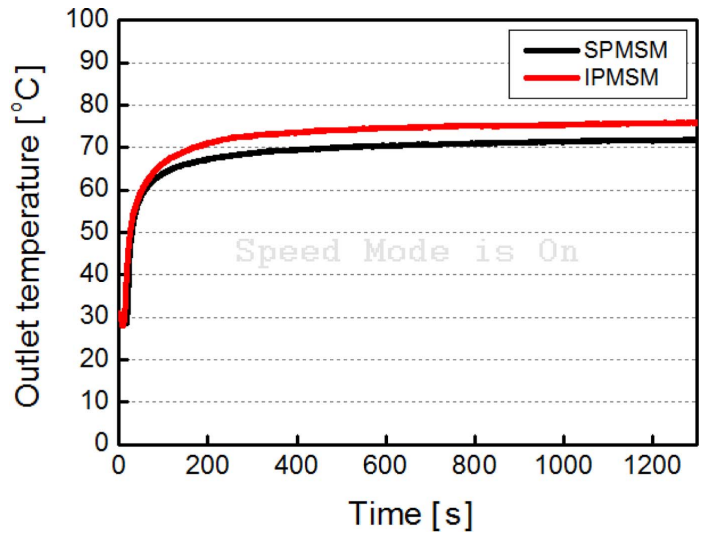

Fig. 15. (Color online) Temperature of the outlet measured at 40,000 rpm.

both motors in common and the output powers are computed as the product of angular velocity and torque estimated by FEA utilizing the measured current shown in Fig. 12(b) and not the shaft powers. At that time, the current phase angle of each motor is applied as $0^{\circ}$ and $25^{\circ}$ respectively and each core loss is also computed along with the torque. Lastly, their copper losses are estimated by Joule's First Law. As a result, the output of SPMSM is larger than that of IPMSM under 30,000 rpm but on the contrary the efficiency is lower. The reason is that except the losses dealt with in this paper additional eddy current losses generated in the sleeve and PM are much larger in the SPMSM [8-10, 32]. However, as the load of blower increases in company with its speed, the efficiency of IPMSM is similar to that of SPMSM because in the IPMSM the influence of copper loss is dominant due to the rapid growth of input current to satisfy the required torque with its low back-EMF. Accordingly, Fig. 15 shows the temperature measured in the outlet of the air blower driven by the IPMSM is slightly higher than that of the SPMSM.

\subsection{Transient Response}

The response capability of the air blower driven through both motors is evaluated in transient state. The performance has a critical effect on the acceleration of a FCEV. Therefore, the air blower should be reached within a short time up to top speed. However, as shown in Fig. 16 , the arrival time up to $40,000 \mathrm{rpm}$ of the air blower driven by the IPMSM is later approximately 0.2 seconds than the SPMSM. The reason is that the voltage measured in the IPMSM is higher than that of SPMSM since 36,000 rpm as shown in Fig. 17 and the controller is optimized only for the SPMSM. Accordingly, the various gains and ramp inputs of the controller is applied for the IPMSM,

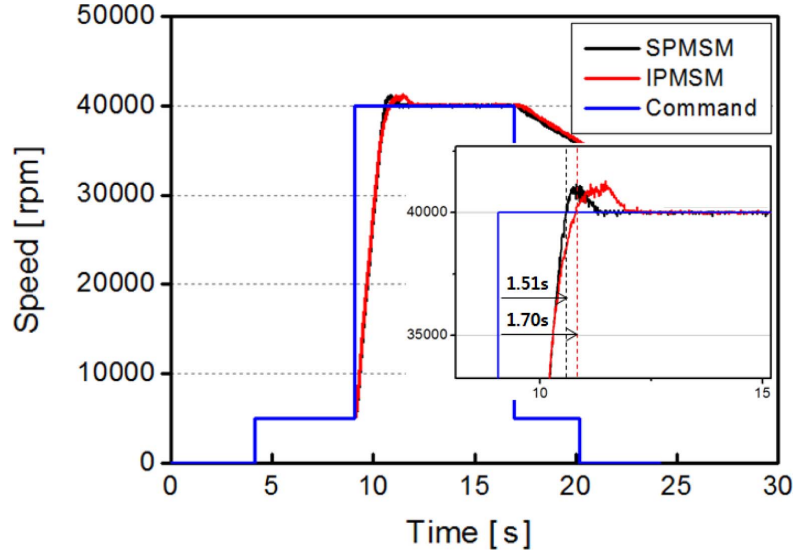

Fig. 16. (Color online) Response capability measured in transient state.

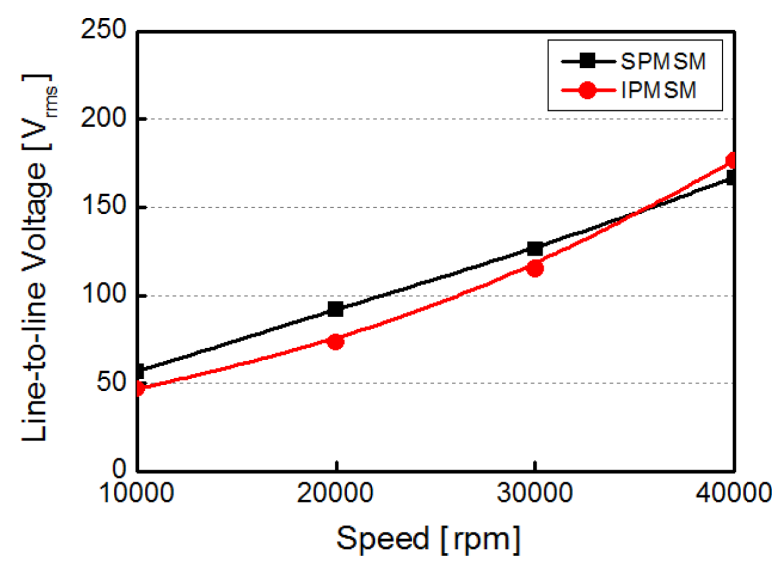

Fig. 17. (Color online) Voltage measured at the air blower system.

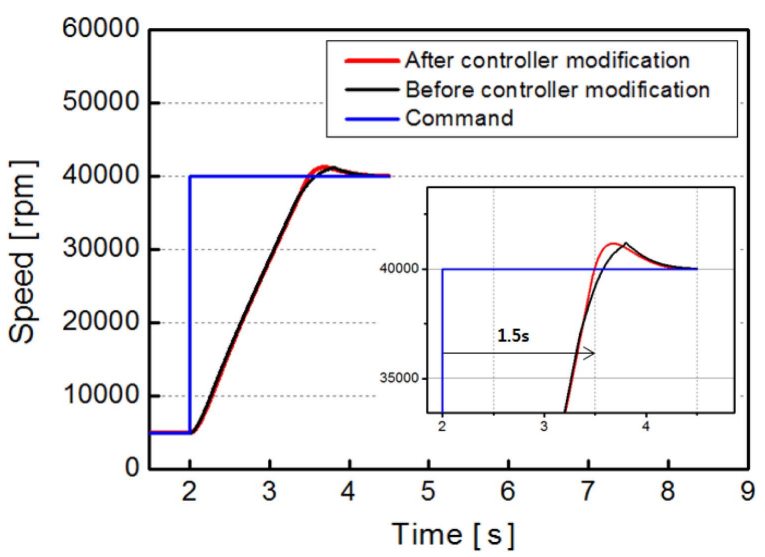

Fig. 18. (Color online) Simulation result of IPMSM with a modified controller.

which is carried out on the basis of control methods proposed in $[33,34]$. The final simulation result is given in Fig. 18. 


\section{Conclusion}

In this paper, the feasibility of an IPMSM with a multilayer rotor configuration is practically demonstrated as a high-speed driving motor for an air blower. Especially, if design conditions such as stator and rotor dimensions, stator winding, and voltage and current limit are equal, the IPMSM compared to a SPMSM not only can reduce the total amount of PM but obtain better performances for the air blower. Nevertheless, it is obviously difficult to design the rotor of the IPMSM. Thus, a parametric design proposed in this paper is very helpful in designing the complicated rotor shape of the IPMSM.

\section{References}

[1] F. Crescimbini, A. Lidozzi, and L. Solero, IEEE Trans. Ind. Electron. 59, 2678 (2012).

[2] T. Raminosoa, B. Blunier, D. Fodorean, and A. Miraoui, IEEE Trans. Ind. Electron. 57, 2988 (2010).

[3] B. H. Bae, S. K. Sul, J. H. Kwon, and J. S. Byeon, IEEE Trans. Ind. Applicat. 39, 811 (2003).

[4] A. Borisavljevic, H. Polinder, and J. A. Ferreira, IEEE Trans. Ind. Electron. 57, 220 (2010).

[5] N. Bianchi, S. Bolognani, and F. Luise, IEEE Trans. Ind. Applicat. 40, 1570 (2004).

[6] A. Binder, T. Schneider, and M. Klohr, IEEE Trans. Ind. Applicat. 42, 1031 (2006).

[7] Jason M. Yon, Phil H. Mellor, R. Wrobel, Julian D. Booker, and Stephen G. Burrow, IEEE Trans. Energy Convers. 27, 646 (2012).

[8] A. M. EL-Refaie, M. R. Shah, R. Qu, and T. M. Jahns, IEEE Trans. Ind. Applicat. 44, 1522 (2008).

[9] H. W. Cho, S. M. Jang, and S. K. Choi, IEEE Trans. Magn. 42, 3521 (2006).

[10] F. Z. Zhou, J. X. Shen, and W. Z. Fei, UPEC2006, 734 (2006).

[11] G. Pellegrino, A. Vagati, P. Guglielmi, and B. Boazzo, IEEE Trans. Ind. Electron. 59, 803 (2012).

[12] R. Schiferl, Ph. D. thesis, Univ. of Wisconsin-Madison, USA (1987).

[13] Z. Han, H. Yang, and Y. Chen, Int. Conf. Electrical
Machines and Systems (ICEMS), 1 (2009).

[14] J. K. Kim, S. Y. Kwak, S. M. Cho, H. K. Jung, T. K. Chung, and S. Y. Jung, IEEE Trans. Magn. 42, 1023 (2006).

[15] A. M. EL-Refaie, R. Manke, and T. M. Jahns, IEEE Trans. Ind. Applicat. 40, 717 (2004).

[16] E. C. Lovelace, Ph. D. thesis, MIT, USA (2000).

[17] S. I. Kim, J. H. Bhan, J. P. Hong, and K. C. Lim, in Conf. Rec. IEEE-IAS Annu. Meeting, CD-ROM (2006).

[18] S. Morimoto and Y. Takeda, Elec. Eng. in Japan 131, 1403 (2000).

[19] Y. Honda, T. Higaki, S. Morimoto, and Y. Takeda, IEE Proc. Electr. Power Appl. 145, 119 (1998).

[20] S. I. Kim, G. H. Lee, J. P. Hong, and T. U. Jung, IEEE Trans. Magn. 44, 1590 (2008).

[21] S. H. Lee, J. P. Hong, J. Y. Lee, Y. K. Kwon, Y. S. Jo, S. K. Baik, and J. D. Lee, IEEE Trans. Appl. Supercond. 17, 1541 (2007).

[22] B. H. Bae and S. K. Sul, in Proc. IEEE Int. Electr. Mach. Drives Conf. 2, 656 (2003).

[23] S. Morimoto, Y. Takeda, and T. Hirasa, IEEE Trans. Power Electron. 5, 133 (1990).

[24] B. H. Lee, S. O. Kwon, T. Sun, J. P. Hong, G. H. Lee, and J. Hur, IEEE Trans. Magn. 47, 1066 (2011).

[25] N. Urasaki, T. Senjyu, and K. Uezato, IEEE Trans. Energy Convers. 18, 41 (2003).

[26] C. Mi, G. R. Selmon, and R. Bonert, IEEE Trans. Ind. Applicat. 39, 734 (2003).

[27] F. Bernal, A. Cerrada, and R. Faure, IEEE Trans. Ind. Applicat. 37, 1265 (2001).

[28] M. Sanada, Y. Inoue, and S. Morimoto, in Proc. ECCE2011, 4189 (2011).

[29] T. Ishikawa, S. Sato, S. Takeguchi, and A. Matsuo, IEEE Trans. Magn. 48, 3132 (2012).

[30] S. I. Kim, Y. K. Kim, G. H. Lee, and J. P. Hong, IEEE Trans. Magn. 48, 843 (2012).

[31] H. Nam, K. H. Ha, J. J. Lee, J. P. Hong, and G. H. Kang, IEEE Trans. Magn. 39, 1472 (2003).

[32] N. Bernard, F. Martin, and M. E. Zaim, IEEE Trans. Energy Convers. 27, 624 (2012).

[33] R. Dhaouadi, K. Kubo, and M. Tobise, IEEE Trans. Ind. Applicat. 29, 919 (1993).

[34] T. Umeno and Y. Hori, IEEE Trans. Ind. Electron. 38, 363 (1991). 